\title{
Necesidad de gobernanza política La esfera política como articuladora y garante en la teoría walzeriana
}

\author{
JOSUÉ GIL SOLDEVILLA \\ Universidad de Valencia (España) \\ josue.gil@uv.es
}

\begin{abstract}
Resumen
Tomando como pretexto la teoría política de Walzer, el presente artículo pretende mostrar la necesidad de política en los tiempos y sociedades actuales. A pesar de lo depauperada y defenestrada que ésta pudiera parecer, sigue siendo necesario articular su papel en nuestras sociedades y mostrar su rol clave para librarnos de problemas tan omnipresentes como puede ser la corrupción en nuestros días. Para ello trataremos de indagar en cuál es el papel de la política y cómo es su relación con la sociedad civil y otras esferas de actuación, poniendo en valor su necesidad.
\end{abstract}

Palabras claves: ciudadanía, corrupción, igualdad compleja, justicia distributiva, participación, política, democracia, sociedad civil, Walzer.

\section{The need of political governance \\ The political sphere as main thrust and guarantor \\ on Walzer's theory}

\begin{abstract}
Using as a pretext Walzer's political theory, this article aims to show the need for politics in our times and contemporary societies. In spite of the impoverished and defunct it may seem, it is still necessary to articulate its role in our societies and show its main role to get rid of omnipresent problems such as corruption nowadays. For all these reasons, we'll try to investigate what is the role of politics and what is the relationship with civil society and other spheres of activity, taking into consideration its need.
\end{abstract}

Key words: citizenship, corruption, complex equality, distributive justice, participation, politics, democracy, civil society, $W$ alzer.

Doctor en Filosofía, Universidad de Valencia (España). 


\section{Introducción}

En los tiempos que corren la pregunta por el papel que la política juega hoy o debe jugar en las sociedades se hace acuciante. Tras numerosos casos de corrupción generalizada en diferentes ámbitos de diversos países y continentes, algunos reniegan de la misma necesidad de la política. Sin embargo, partiendo del pensamiento de Michael Walzer, y tomando en consideración algunas otras referencias - como los planteamientos de Adela Cortina-, en este artículo pretendo mostrar, cómo hoy más que nunca la política es necesaria y no la podemos obviar. La necesidad de una esfera política sana, en la que se definan usos y funciones, es una de las piedras angulares en el pensamiento walzeriano para que los objetivos de justicia e igualdad en las sociedades puedan cumplirse.

Este artículo tiene por objetivo mostrar la perspectiva y aportaciones de Walzer, partiendo del panorama actual e indagando en la necesidad de gobernanza política, por más que algunos se empeñen en infravalorar su necesidad en nuestro tiempo. Para ello divido mi artículo en tres epígrafes: primero, comienzo con el problema de la corrupción en nuestras sociedades actuales; segundo, continúo con la necesidad imperiosa de gobernanza política y cómo la esfera política juega un papel relevante como articuladora y garante de justicia; y tercero, para finalizar, analizo la relación entre la esfera política y la sociedad civil.

\section{El problema de la corrupción}

Podemos definir la corrupción como el conjunto de actitudes y actividades mediante las cuales una persona transgrede compromisos adquiridos con otras personas, utilizando los privilegios otorgados, los acuerdos tomados, con el objetivo de obtener un beneficio ajeno al bien común (Lozano, 2011: 145; Garzón Valdés, 1997: 39ss.). En las organizaciones, especialmente en las públicas, es la práctica consistente en la utilización de las funciones y medios de aquellas en provecho, económico o de otra índole, de sus gestores. Transparency International define corrupción como el mal uso que se hace del poder que te han confiado para obtener beneficios privados. Normalmente hablamos de corrupción cuando reconocemos la intervención irregular de la lógica del dinero y el anhelo de poder e influencia en transacciones y actividades humanas en las que se ponen legítimamente en juego otra clase de bienes sociales y recursos. Por lo general, tal intromisión se ejecuta con la intención de lograr un beneficio particular, muy habitualmente asociado al poder y al dinero (Gamio, 2008: 40; Malem, 1997: 73ss.). 
Tomando en consideración lo dicho anteriormente, si bien hay muchas definiciones con diferentes matices del término corrupción, querría partir del significado que Walzer le da a lo largo de su obra y que tiene que ver con el contrario a la definición de igualdad compleja. De este modo, entenderemos el término corrupción como la colonización de esferas sociales heterogéneas por parte de los bienes internos del espacio económico y político. Algunos ejemplos de ello vienen definidos por los usos obstruidos o prohibidos del dinero (Walzer, 1983: 282-284), si bien la corrupción puede tomar otras muchas formas como el soborno (Álvarez, 1997), el cohecho, la extorsión, el tráfico de influencias, el fraude (Lamo, 1997: 271), la malversación, etc. ${ }^{1}$, todos ellos asuntos de portada en nuestros días, normalmente relacionados con el poder político y económico, con un fuerte impacto y efectos perniciosos para nuestras sociedades.

Sin embargo, dentro del ámbito privado también encontramos conductas inaceptables. A modo de ejemplo, siguiendo a Walzer, podemos ver el caso de un hombre acaudalado que soborna a un funcionario público con el fin de que pueda influir en un fallo absolutorio de un proceso penal en el que está inmerso. Podemos imaginar otros casos como el de un estudiante que quiere obtener un título en una universidad de prestigio, e intenta hacer valer la influencia política de su padre para lograrlo; una empresa de paneles solares que pretende cerrar un cuantioso contrato con algún determinado gobierno, y para ello propone un soborno a la autoridad competente; un presidente autonómico que intenta ser reelegido en su comunidad y usa dinero público para financiar su campaña, además de donaciones al margen de la ley. Todos estos casos son ejemplos evidentes de corrupción. Todas son conductas moralmente inaceptables y susceptibles de reprobación y castigo en el plano moral y legal.

Como puede observarse, el fenómeno de la corrupción va más allá de los límites del dominio de la función pública o el estado, pues su práctica puede ser percibida también en contextos de la esfera privada como empresas, universidades, fundaciones..., y de forma general en instituciones no públicas (Gamio, 2008: 40-41). Hay prácticas y transacciones en las cuales deben contar como criterios distributivos subyacentes a sus prácticas la igualdad ante la ley, el talento académico, la competitividad, la solidaridad, como debía ser en los ejemplos mencionados en las líneas precedentes. El poder y el dinero no deberían tener lugar, pues su intromisión distorsiona tales actividades, sus reglas y sus exigencias internas

1 Doy por supuesto el conocimiento de los significados de todos estos términos, si bien puede consultarse sus definiciones ampliadas en Lozano (2011: 146-147) y Laporta (1997: 21-22). 
de transparencia y razonabilidad. En estos casos, hablaríamos de corrupción y desde el punto de vista filosófico que Walzer establece, de la invasión del poder económico o político en unas esferas de justicia distintas a las suyas. Cuando estos actos se convierten en habituales, la corrupción puede llegar no sólo a ser escandalosa, sino a convertirse en una forma de tiranía y dominación. Como dice Emilio Lamo refiriéndose a España y otros países como Italia, Brasil, Venezuela, Japón, la corrupción ha afectado sustancialmente a casi todo el establishment político y a muchas de las grandes empresas. No han sido casos aislados, sino un sistema, una trama y una práctica generalizada (Lamo, 1997: 273).

\section{Corrupción, mercado y regulación}

En este sentido, cuando Walzer (2008), en un simposio de la fundación Templeton, es interpelado sobre si el mercado libre corrompe el sentido moral, responde de forma taxativa que evidentemente lo hace. Para nuestro autor, la corrupción va ligada al mercado pero no por el mercado en sí mismo sino por la falta de regulación de éste y la falta de cortafuegos para que no haya corrupción en él. Hay que decir que Walzer considera más peligrosa la corrupción política que la económica ${ }^{2}$. En cualquier caso, aunque para la esfera política se han establecido más cortafuegos, la económica está falta de regulación, hecho que la convierte en muy peligrosa.

Hoy la peor forma de corrupción no proviene del ámbito político (pese a sus imperfecciones), sino del ámbito económico, caracterizado por un mercado desregulado, en el que los comportamientos no están encuadrados y cuya responsabilidad es casi nula (Walzer, 2008: 20).

En consonancia con este planteamiento, Emilio Lamo sostiene que «el verdadero problema es un sistema insuficientemente provisto de controles y de contrapoderes» (Lamo, 1997: 284). Mientras en política, si bien hay corrupción, hay muchos más filtros y los políticos están muy

2 Lozano (2011: 147) afirma que la corrupción política es la más grave por tres razones fundamentales: se engaña a mucha gente, tiene el poder de generar corrupción en otros ámbitos (económico sobre todo), y genera enorme desconfianza, porque las administraciones públicas son quienes deberían luchar contra todo tipo de corrupción. A nivel político la corrupción hace que los ciudadanos desconfíen de los políticos y de las instituciones públicas, que estén dispuestos a no cumplir sus directrices e incluso engañarles, si pueden. La corrupción en los procesos electorales y en los cuerpos legislativos y judiciales reduce la responsabilidad y distorsiona la representatividad de los elegidos. Además, la corrupción también dificulta el desarrollo económico y genera distorsiones e ineficiencias. 
observados, a pesar de que en estos tiempos que corren no parezcan haber sido muy efectivos, los hombres de mercado cada vez tienen menos regulaciones y esa clase de poder se extiende inevitablemente hacia la política $y$, por ende, al resto de esferas ${ }^{3}$. Lo sorprendente es que no tratemos de la misma manera los riesgos inherentes al mercado que los derivados de la política. Sobre esto, Walzer (2008: 20) manifiesta que, allí donde las democracias han tenido éxito (mediante constituciones políticas) para emanciparse de los caprichos de los tiranos y de la arrogancia de los aristócratas para poner fin a las peores formas de la corrupción política, los mercados han sido abandonados a sí mismos. En el caso del mercado, hay poca regulación y el mero hecho de tener poder casi ilimitado hace que puedan hacer prácticamente de todo. Walzer llega a afirmar que en el caso de EEUU «no tenemos constitucionalismo económico», que ponga límites a la esfera económica. Además, bajo su visión, en EEUU, y podríamos extenderlo con algunas salvedades al resto de países occidentales, los contrapoderes de los sindicatos se han debilitado considerablemente, el sistema de impuestos se ha vuelto regresivo de manera desproporcionada, la regulación de la banca, de la inversión, de los fondos de pensiones... es «totalmente» ${ }^{4}$ inexistente (Walzer, 2008: 22) y la arrogancia de la élite económica, que tiene la convicción de ser libre de hacer todo lo que le venga en gana, es sideral. Este tipo de poder, tomando una frase prestada de Lord Acton, es el más corruptor y hoy parece que la afirmación de que el poder corrompe, y el poder absoluto corrompe absolutamente, posee una incontestable validez. Progresivamente gana la esfera pública, dónde la influencia del dinero ganado sin restricciones en un mercado no regulado, amenaza la moral política misma ${ }^{5}$.

Para Walzer, la competición que mueve a los mercados hoy alienta a los actores a romper las reglas morales y a buscar buenas razones para hacerlo. Son esas racionalizaciones, que llevan a algunos a engañarse a sí

3 Por ejemplo, Walzer (2008: 20-21) relaciona la financiación de campañas electorales a cambio de cierta legislación posterior o favorecer ciertos intereses.

4 Obviamente la expresión es hiperbólica para mostrar la falta de mayor regulación.

5 En este mismo sentido, Lamo (1997: 288) pone de relieve que existe actualmente una coyuntura en la que inciden varios factores: una nueva ética económica marcada por las actividades financieras especulativas a corto plazo, una especie de economía de casino que está sustituyendo al espíritu empresarial tradicional; la desregulación, descentralizaciones, eficiencia del mercado y privatización que implica menos controles, aunque paradójicamente con mayor injerencia de los políticos, y el bloqueo de controles institucionales. Como vemos, Lamo suma causas y condiciones, pero en especial señala «el bloqueo de los controles institucionales», es decir, la impunidad como un elemento distintivo de esta «coyuntura» institucional. De este modo, la influencia en la vida democrática de este bloqueo alimenta la desconfianza pública produciendo deslegitimación. 
mismos para traspasar sin escrúpulo determinadas líneas rojas, las que corroen y socavan el sentido moral, «echando a perder» y «trastocando la forma genuina de algo», como dicta el sentido originario de la expresión latina corrumpěre.

Si hacemos una analogía con el sistema político democrático, encontramos que junto con los proyectos loables en los que la empatía, el respeto mutuo, la solidaridad, la amistad, se desarrollan y refuerzan construyendo un tipo de carácter, conviven la competición por el poder, que pone a las gentes bajo una fuerte presión incitando incluso a los candidatos a mentir en las reuniones con sus electores, a hacer promesas imposibles de cumplir, a aceptar dinero sucio, etc. Obviamente, todas estas formas de corrupción tienen un fuerte impacto en nuestra confianza en la democracia y corrompen nuestra moral. Con Walzer vemos cómo elecciones libres y libre mercado nos enseñan no tan solo a arriesgarnos, a intercambiar y a deliberar colectivamente, sino también a vigilarnos y a desconfiar los unos de los otros, a traicionar a nuestros amigos, etc. De este modo, la corrupción altera y desnaturaliza los procesos distributivos en los que se entromete.

\section{Condiciones y consecuencias de la corrupción}

Ciertamente, la corrupción es una práctica instrumental, esto es, quienes incurren en ella la ejercitan como un medio para lograr algún provecho personal o corporativo violando las normas de las instituciones y lesionando el derecho de otras personas, sin embargo, sus consecuencias e impacto van mucho más allá de lo que las acciones individuales pudieran sugerir.

Por todo ello, resulta imperativo preguntarse por las condiciones y factores que promueven los actos de corrupción en una sociedad y que contribuyen a la degradación moral y política de las instituciones. Entre los factores que generan el caldo de cultivo para la corrupción podemos destacar con Lozano (2011: 147-148) los siguientes: que puedan haber unas estructuras de gobierno adversas, un funcionamiento deficiente de la democracia, limitaciones o mal funcionamiento de derechos como la libertad de expresión y la libertad de prensa, déficit de información, la existencia de funcionarios públicos mal pagados, unas condiciones sociales que favorezcan una población apática, poca cultura política, una valoración relajada de valores como la honestidad, déficits legales..., y es que, cuando la concentración del poder político está en pocas manos, la ausencia de fiscalización efectiva desde el ámbito del estado y la sociedad civil contribuyen a la constitución de situaciones de impunidad frente a la acción de la justicia, que a su vez refuerza las conductas corruptas y co- 
rruptoras (Gamio, 2008: 42-43). Todo ello da lugar a que el ciudadano se sienta desmoralizado, creándose en él modos de pensar y actuar, que en muchos casos pueden llegar a ser, condescendientes con la corrupción. Poco a poco, esta condescendencia y sentimiento de impotencia robustecen las determinaciones sociales e ideológicas que favorecen la práctica de la corrupción. Cuando los miembros de la sociedad se convencen, y a veces constatan, que la comisión de delitos de corrupción no genera consecuencias penales, morales y políticas de consideración, los lazos de confianza (Cortina, 2003) y respeto entre los conciudadanos y representantes se tornan raquíticos y como resultado de ello, la comunidad se debilita peligrosamente, al grito de sálvese quien pueda, debilitando así el sentido de pertenencia comunitaria y ciudadanía.

En este sentido, como puede verse, el «impacto de la corrupción tiene enormes efectos políticos, sociales y económicos más allá del dinero o del valor material de los bienes en juego ya que debilita la confianza en las instituciones públicas, erosiona gravemente la democracia y dificulta el funcionamiento de la administración» (Lozano, 2011: 147), pues corroe valores democráticos como confianza, transparencia, justicia y tolerancia (Urbinati, 2010: 65-66).

En su célebre tratado Los oficios, Cicerón señalaba que las personas pueden obrar injustamente de dos maneras. En primer lugar, activamente, cuando el individuo, a través de la comisión de un delito o una falta, lesiona expresamente el derecho de un tercero o vulnera el sistema constitucional. En segundo lugar, pasivamente, cuando los agentes deciden mirar hacia otro lado, sea por desidia, temor, indolencia o complicidad, en circunstancias en las que el derecho de alguien es conculcado o se pretende violar el estado de derecho (Shklar, 1988). Con este gesto el individuo renuncia de facto a parte del cumplimiento de su deber como ciudadano. Es por esto por lo que el excesivo repliegue de las personas hacia su vida privada, como pretendían los liberales extremos, nunca ha sido positivo para la lucha contra la corrupción (Walzer, 1984a; Andrés, 2013). La ausencia de control ciudadano y la apatía consolidan estas prácticas deshonestas (Gamio, 2008: 44). En este sentido, la injusticia pasiva nos convierte en seres indefensos ante el poder de quienes logran privilegios indebidos infringiendo las normas. Como señala Lamo (1997: 284), las prácticas corruptas tienen el efecto de marginar o discriminar a los que se niegan a cooperar y por ello se va ampliando el círculo de los que participan para no quedar fuera del cargo que ocupan; todo esto va exten-

Por el contrario, y para crear unos hábitos opuestos a los expresados por la corrupción, pueden verse trabajos como los de Cortina (2003) o García Marzá (2004). 
diendo el círculo de la impunidad como la imagen de los círculos concéntricos que produce la caída de una piedra en el agua.

\section{Buscando antídoto}

La lucha contra la corrupción y la impunidad requiere de instituciones democráticas sólidas y un sentido fuerte de ciudadanía, cómo afirmaban Walzer y Pettit a propósito de la dominación (Gil Soldevilla, 2004), que no es sino un aspecto más genérico de algunas formas de corrupción. Sin ciudadanos vigilantes, sin vecinos, trabajadores, consumidores, estudiantes y feligreses vigilantes, la corrupción y el autoritarismo prosperan sin resistencia alguna, en todas sus formas y contextos.

Por todas estas razones la esfera política y el papel de la ciudadanía se antojan importantísimos a la hora de poner límites y crear las condiciones para sociedades más justas en las que los propios agentes puedan tener los recursos necesarios para el control democrático y la defensa de la ética pública. Asimismo, la construcción y el uso de los canales y espacios de acción común resultarán esenciales para que esta lucha ciudadana se cristalice en prácticas reales de movilización, crítica y construcción. En este sentido, tanto el estado como la sociedad civil ofrecen tales espacios de deliberación y compromiso cívico y sobre ellos tendremos algo más que decir (Cortina, 1997).

\section{Necesidad de gobernanza política La esfera política como articuladora y garante}

Visto el problema de la corrupción como una transgresión de fronteras, donde la quiebra de los significados sociales oportunos es la base para conseguir bienes que no debieran estar al alcance por medios y prácticas que no son inherentes a los propios significados sociales que nos hemos dado y habiendo visto como este problema no hace sino que los ciudadanos pierdan la fe en la coherencia entre lo que se dice y lo que se hace, causando desmotivación y pérdida de interés por la cosa pública o indiferencia, cuando no indignación y hastío, creo necesario ver el papel que la esfera política debiera tener para limitar estos efectos y garantizar los conceptos claves en la teoría walzeriana de justicia distributiva e igualdad compleja contra los que la corrupción extiende sus redes, al intentar obtener por medios impropios aquellos bienes que ansía. Para este fin será determinante el papel que la esfera política ejerza en las sociedades, ya que, como veremos, juega un papel dual que no tienen el resto de esferas. 
En este sentido, hemos de advertir que la política puede ser el camino más directo al predomino, pudiéndose convertir en el bien más peligroso de la historia humana (Walzer, 1983: 15) ${ }^{7}$. De hecho, a pesar de la importancia que la esfera económica con sus intromisiones puede tener, como anteriormente enunciamos a propósito de la corrupción, es la política, como esfera ambivalente, la que juega un papel determinante, incluso para la convertibilidad y predomino de la esfera del dinero y el mercado y su capacidad operativa ${ }^{8}$.

El problema central que habremos de afrontar al tratar la esfera política es, en ocasiones, la no distinción entre que la esfera política sea dominante en las esferas y separaciones, como de hecho lo es, y dentro de las esferas. Esta será una de las razones, según Miller, por las que «Walzer desconfía del poder político y teme que permitir al estado operar dentro de las esferas de la justicia signifique abrir las puertas a la peor y más simple forma de tiranía: la asignación coercitiva de bienes sociales». Recordemos que, «la igualdad compleja es la encarnación plena del arte de la separación liberal, cuyo principal logro fue la limitación del poder estatal» (Miller, 1995: 25) ${ }^{9}$. De este modo, siguiendo a Walzer, afirmamos que el Estado debe ser una institución que también se encuentre «separada» del resto, con el fin de quedar en manos de los ciudadanos al igual que las iglesias quedan en manos de los feligreses o las universidades de los profesores y estudiantes..., de manera que, los ciudadanos no sean libres frente al Estado como ciudadanos, sino en el Estado y en su calidad de creyentes, estudiantes, padres, trabajadores... Es así como el Estado se convertirá en garante y defensor de las separaciones y diferenciaciones establecidas, velando por la integridad institucional de éstas y la suya propia. Igualmente hemos de ser conscientes que las separaciones no son absolutas y que el mismo Estado, o la esfera política, influirá enormemente en la configuración del mapa social reinante.

En cualquier caso, Walzer (1993) admite que el poder político no tendrá más remedio que inmiscuirse en otras esferas, como por ejemplo, en la economía de mercado, a fin de recaudar fondos para financiar el

El predominio es uno de los mayores problemas que Walzer señala para el desarrollo de la igualdad compleja y la consecución de sociedades justas.

8 En este sentido, podemos afirmar que la riqueza excede los límites de su ámbito y, en consecuencia, de la misma manera que el poder político del estado habrá de limitarse para que no interfiera arbitrariamente y más de la cuenta en nuestra actividad individual, la riqueza y el dinero tampoco debieran poder comprar todo lo que les viniera en gana, por más que se establecieran estas operaciones como acuerdos entre particulares.

Recordar que si bien este fue uno de sus principales logros, dejó el camino abierto para que el dinero lo gobernase todo, de modo que su lucha por la libertad arrojaba déficits de igualdad que debían ser subsanadados. 
sistema de bienestar social, impedir los intercambios obstruidos o prohibidos, etc. De todos modos, y aun admitiendo estos riesgos, Walzer enfatiza el papel positivo del estado en las distribuciones y contra la injusticia, tanto dentro de las esferas como entre ellas. Asimismo, subraya el papel axial desempeñado por la ciudadanía (Walzer, 1984b; 1989; 1995; 1997) y el papel central de la sociedad civil densamente tejida, con múltiples asociaciones participativas capaces de crítica (Walzer, 1992) en relación con la esfera política de la que nos estamos ocupando. No hemos de olvidar que, en cierto sentido, la esfera política jugará un papel de garante entre los conceptos de justicia distributiva e igualdad compleja ya que, en relación a la justicia distributiva, será la esfera política la que delimite los campos de actuación del resto de las esferas y, respecto a la igualdad compleja, la esfera política tendrá un papel importante al no permitir la convertibilidad de unos bienes en otros impidiendo así el predominio y disminuyendo el poder de los bienes dominantes.

\section{El carácter dual de la esfera política}

De este modo, podemos afirmar que la política como esfera desempeña un papel dual e importantísimo en el proceso de distribución y, por tanto, en la consecución de sociedades justas e igualitarias. Su doble carácter viene definido, en primer lugar, porque la esfera política es como cualquier otro bien que la gente valora, intercambia, comparte, etc., a veces es dominante, a veces es ampliamente compartido, otras veces sólo lo tienen unos cuantos, etc. (Walzer, 1983: 15). El problema surge cuando el poder político se convierte en predominante e invasivo. Es en ese momento cuando tenemos un problema real, un problema que la igualdad simple no podrá resolver por más que queramos repartir el poder político entre todos de una manera igualitaria. Es por esto por lo que la solución, para Walzer, vendrá más del intento por limitar a los agentes restrictores y establecer barreras constitucionales de forma eficiente que impidan su predominio. A su vez, la definición y la imposición de estos límites al poder político serán más importantes cuando el resto de monopolios sociales y económicos hayan sido destruidos (Walzer, 1983: 15). En teoría, el poder político es el bien dominante en una democracia, y es convertible en la manera en la que los ciudadanos elijan. Pero, en la práctica, al destruir el monopolio del poder se neutraliza su predominio, de modo que no podrá ser ampliamente compartido sin estar sujeto al empuje de los otros bienes que los ciudadanos posean o esperan poseer (en este sentido, hay que advertir que los monopolios de otros bienes, como el mérito, la técnica... podrían reaparecer). De ahí que la democracia sea 
un sistema que refleja con bastante rigor la distribución de los bienes sociales $^{10}$.

En segundo lugar, el ámbito de la esfera política es distinto de cualquier otra cosa, pues no sólo es una esfera más sino que, a su vez, es también el agente regulador de los bienes sociales en general distribuidos a través de esferas. En este sentido, la esfera política marca y delimita la convertibilidad y el ámbito del resto de esferas, teniendo en suma la función de defender fronteras (incluso la suya). De este modo, vemos cómo las esferas distributivas están mediadas por el poder político y cómo éste ha de hacer valer los significados compartidos de lo que los diferentes ámbitos de la vida o esferas son y significan. Al comparar el pensamiento de Walzer y el de un republicano como Pettit (Gil Soldevilla, 2004) observamos cómo ambos son favorables a posibles interferencias del estado en favor de la libertad como no dominación, en la medida en que éste ponga límites a cualquier práctica opresiva y reduzca la tiranía social que determinados grupos ejercen sobre otros. Su interferencia debe ser tan sólo en apoyo contra la opresión y no debe extralimitarse en su poder, pues podría acabar siendo la misma esfera política una esfera tiránica (peligro, por desgracia, muy frecuente como la historia muestra). De ninguna forma se tratará de interferencias arbitrarias no consentidas sino sólo de interferencias pactadas previamente a favor de la libertad como no dominación.

En cualquier caso, no es difícil observar cómo este poder también podrá ser usado para invadir esferas distributivas en detrimento de lo que éstas significan, contraviniendo las comprensiones compartidas socialmente en aras de otros intereses. Es por esto por lo que el estado no sólo tendrá la función de garantizar la independencia de las esferas y sus criterios, tampoco únicamente preocuparse por cómo se distribuye el poder político, sino que, además, el estado, ha de ser un instrumento a favor de la redistribución y, en este sentido, el poder político ha de desplegarse también por razones legítimas a través de otras esferas ${ }^{11}$, pues es frente al Estado ante quien llegan los diferentes reclamos. En consecuencia, su papel no se limitará sólo a la relación entre las esferas, sino también dentro de ellas y, en este sentido, dirá Walzer que para poder prevalecer so-

\footnotetext{
10 A la base de esto, se sugiere el pensamiento de que sociedades con distribuciones de este tipo podrán dar lugar más fácilmente a democracias en diferentes formas, si bien Walzer (1983: 15) no se compromete con tal efecto y reniega de hacer una relación causa-efecto del mismo.

11 Walzer (1993: 149) reconoce esta última afirmación como un déficit que se había presentado en sus anteriores trabajos, no llegando a comprender el papel total que el poder político ha de desarrollar, sobre todo en sociedades democráticas.
} 
bre nuevos monopolios dominantes ${ }^{12}$ o exclusiones sistemáticas, el Estado deberá ser poderoso, incluso intervencionista en parte, si es que pretende cumplir con los objetivos encomendados por principios como el de la diferencia de Rawls o cualquier otro (Walzer, 1983: 15) en busca de mayor igualdad y, sobre todo, justicia social, que es de lo que un estado se debe ocupar (Cortina 1994).

\section{Frente a la exclusión y hacia la ciudadanía: necesidad de interpretación e interdisciplinariedad}

De esta forma, si bien podemos ver como en algunas sociedades se reproduce la exclusión de determinados grupos y gentes de manera injusta a través de todas las esferas, habremos de afirmar que una de las primeras redistribuciones a fraguar será el promover y permitir que los excluidos gocen de poder político en tanto que ciudadanos. Se trataría de abrir la posibilidad a todos los ciudadanos, independientemente de su raza, etnia o religión, de participar en todas las esferas de las que hasta el momento quedaban excluidos. En este sentido, dirá Walzer (1983: 15): «cuando los ciudadanos y dirigentes contribuyen a reformar el estado, están colaborando al mismo tiempo a reformar la sociedad, convirtiéndose en promotores y agentes de la igualdad compleja».

De hecho, la existencia de grupos de excluidos, muestra como no sólo tendremos que defender las fronteras sino que será necesario volver a trazarlas y redefinirlas desde dentro, en función de los significados sociales que tengan los bienes en juego. Debemos recordar en este punto que las diferenciaciones y separaciones son inevitablemente dependientes de los procesos interpretativos llevados a cabo a través de la actividad común. Todas las respuestas que podamos dar acerca de dónde han de situarse las fronteras, cuáles son los significados de estas, qué criterios imperan dentro de las mismas, etc., no son sino fruto de la actividad común interpretativa al analizar y proveer de significado social los diferentes bienes a distribuir (Walzer, 1984a).

En este sentido, tanto el poder del estado como los ciudadanos habrán de participar en un proceso interpretativo conjunto y cooperativo que dé sentido a los bienes sociales y sus distribuciones, lo que demuestra que las fronteras no son fijas y pueden ser impugnadas en cualquier

\footnotetext{
12 Nuestro énfasis no debe ponerse tanto en reducir el monopolio de ciertos bienes a lo largo del tiempo, pues siempre aparecerán oportunidades para algunos bien posicionados para aprovechar y explotar los bienes importantes, sino que deberemos considerar ante todo la reducción del predominio, la cual es la cuestión central para salvaguardar la justicia distributiva (Walzer, 1983: 16).
} 
momento. De este modo, vemos que la esfera política está implicada en todos los acuerdos y desacuerdos sobre la distribución. El Estado no podrá ignorar todo lo concerniente a las diferentes esferas de justicia. Sin embargo, su papel ha de ser restringido por el grado de autonomía relativo de las diversas esferas. En relación con esto, hemos de ser conscientes de que cuando se interpreta, cuando se definen significados y distribuciones, se hace codo con codo, entre todos, pero teniendo en cuenta especialmente a los más próximos a las esferas en cuestión, de modo que profesores, médicos, padres, sindicalistas, trabajadores, empresarios, periodistas, feligreses, etc., sean los primeros en ser tenidos en cuenta a la hora de trabajar los significados y sus distribuciones en las diferentes esferas $^{13}$. El Estado, al menos el que busque legitimidad, no podrá convertirse en usurpador sino que ha de ejercer el papel de garante y coayudante estratégico para que estos procesos sociales discurran normalmente.

Por todas estas razones, vemos con Walzer cómo el carácter del poder político en cierto sentido siempre será dominante en las fronteras y separaciones. Cuando éstas están bien definidas y los bienes se reparten dentro de las esferas por los criterios oportunos, el estado sólo cumple un papel de garante de fronteras y poco tendrá que decir, pero cuando algunas esferas, o algunos dentro de ellas, intentan ir más allá, el estado, a instancias de la oposición, los indignados, disidentes o la ciudadanía en general a través de las diferentes asociaciones de la sociedad civil, debe implicarse una vez más para redefinir los significados sociales, sus respectivas distribuciones, influencias y campos de actuación ${ }^{14}$.

Aun así, hemos de reconocer con Walzer, que todavía el estado y la esfera política tienen más ámbitos legítimos de actuación pues, a veces, no se trata «tan sólo» de redistribuir sino también de aumentar bienes disponibles. En este sentido, no podemos obviar la gran cantidad de decisiones de tipo político que exceden a las propias esferas y que incumben a todos los ciudadanos en su conjunto. Pensemos, por ejemplo, en el sistema educativo y las ratios alumno profesor, la construcción de nuevos centros educativos, hospitales, infraestructuras, las decisiones relativas a las políticas sociales, fiscales, etc. En este sentido, la esfera

13 Sobre este punto, creo que la hermenéutica de las actividades humanas, desarrollada por Cortina (1996), es fundamental, así como el desarrollo de las éticas de las profesiones y la construcción conjunta del mundo que habitamos.

14 De este modo, vemos que la actuación de la esfera política no es sólo entre esferas sino también, cuando es preciso, dentro de las esferas, constituyendo así una modificación sustancial del planteamiento inicial de los primeros escritos walzerianos. 
política, en la figura del Estado ${ }^{15}$, debe defender, según Walzer, los valores de la complejidad y la igualdad en representación de los intereses de todos los ciudadanos, pues la inserción de los excluidos comienza con la ciudadanía, como «valor reproducido por la actividad política democrática en todas las esferas de justicia» (Walzer, 1993: 152).

Sobre este último punto, cabe recordar lo dicho por Walzer (1986) acerca del último requisito a propósito de la justicia distributiva estadounidense y que tenía que ver con la necesidad de una democracia fuerte (Barber, 1984; Chapa, 2011), democracia que obviamente debía estar anclada en la igualdad de oportunidades, pues el poder político ha de estar disponible para todos los ciudadanos. Este requisito desempeña un papel crucial $^{16}$ pues el poder político determina y establece las prioridades estatales en materia de infraestructuras, prestaciones sociales, etc., pudiendo condicionar las oportunidades reales de las que los ciudadanos disponen en el resto de esferas. En este sentido, Walzer exige una apertura real de la esfera política a los ciudadanos y, por este motivo, considera fundamental el éxito de la sociedad civil. Sus asociaciones y participación en las diversas actividades dentro de las diferentes esferas de justicia tendrán un rol fundamental, junto con el estado obviamente, para el éxito de la igualdad compleja, pues en la sociedad civil las asociaciones «contribuyen a descentralizar las esferas de justicia multiplicando los dispositivos y los agentes, favoreciendo una mayor variación en la interpretación de los criterios que se aplican en la distribución de los bienes» (Walzer, 1993: 145).

\section{Poder político y sociedad civil}

Adentrándonos un poco más en el concepto de sociedad civil (Walzer, 1992) y su papel, hemos de decir que éste sirve de nexo entre la esfera política, como ha sido tratada, y el concepto de ciudadanía, pues a través de la sociedad civil se produce y reproduce el espíritu cívico, fundamental en nuestros días si queremos que la esfera política juegue su papel y sólo el suyo (González, 2013). Al igual que para otros teóricos como Barber, la sociedad civil para Walzer tiene una conexión con la política no pasajera, convirtiéndose en indispensable para la democracia.

15 Walzer (1993: 151) está pensando sobre todo en los estados democráticos modernos.

16 Tanto es así que algunos como David Miller han visto en ello el eje central de la propuesta walzeriana de igualdad compleja, asimilando esta igualdad de oportunidades en su base a una especie de igualdad de estatus relacionada con la igualdad de ciudadanía. 
En este sentido, dirá Barber (2000: 13), la sociedad civil contribuye de forma esencial a la democratización de las sociedades, llegando a afirmar que sin ella los ciudadanos están desamparados ante la posibilidad de encontrar un lugar para todos (Conill, 2013).

Por sociedad civil entendemos el espacio de acción humana sin coerción y también el conjunto de relaciones en nombre de la fe, la ideología, los intereses, la familia..., que llenan ese espacio. Sindicatos, asambleas vecinales, iglesias, partidos, cooperativas, movimientos a favor de determinados valores, etc., todas estas tramas asociativas forman lo que denominamos sociedad civil (Walzer, 1992: 32) ${ }^{17}$. La sociedad civil tiene su origen en la lucha por la libertad religiosa, por la creación de espacios de libertad en los que las diferentes opciones pudieran desarrollarse. Estos espacios de libertad extendidos a otros ámbitos es lo que da lugar a la pluralidad de asociaciones y motivos por los que los seres humanos en sociedad se asocian libremente y sin coerción (Walzer, 1992: 36) ${ }^{18}$.

No obstante, para Walzer, no se puede escapar del todo a cierta coerción y no es posible escoger pertenecer sólo a la sociedad civil. El estado y su poder siguen siendo necesarios a pesar de todo, si bien la sociedad civil ha de ejercer el contrapeso justo para que el estado no se convierta en despótico. Ningún estado puede durar mucho tiempo si se aleja de la sociedad civil pues los valores de lealtad, espíritu cívico, competencia política, confianza en la autoridad, etc., nunca han sido sólo obra del estado. El reconocimiento de la pluralidad de la vida asociativa es y debe ser una exigencia para el estado. Sin embargo, tampoco la pluralidad de la sociedad civil por sí sola es autosuficiente y autogeneradora, como pensaban los liberales (Walzer, 1992: 36; Dekker, 2008).

Aunque pueda resultar paradójico, esto tiene que ver con el argumento acerca del carácter dual de la esfera política expresado anterior-

17 Cortina la define como un espacio «no sometido directamente a la coacción estatal» (Cortina, 1998: 354). Véase, al respecto, el interesante número temático de la revista Recerca editado por García Marzá \& Feenstra (2008), titulado "Sociedad civil: una perspectiva crítica".

18 A lo largo de todo el artículo Walzer hace un repaso de las diferentes respuestas que se han dado desde la izquierda, el republicanismo, el capitalismo y el nacionalismo, terminando con una quinta repuesta que pretende ser una síntesis que parte del hecho de que la sociedad civil es un hecho innegable, anclado en nuestra naturaleza social y compleja. La sociedad civil sería así el reino de la fragmentación y la lucha pero también de identidades concretas y auténticas. Es el marco en el que vivimos, y lo que configuremos dependerá de la fuerza y vitalidad de las asociaciones que se den en su seno. Sin embargo, esta visión liberal de la misma, constituida en anti-ideología de las anteriores también tiene sus problemas y no podrá prescindir del poder estatal por mucho que lo anhelase. 
mente. La ciudadanía podría ser un rol más que los ciudadanos representan pero el estado no se parece al resto de asociaciones. El estado enmarca a la sociedad civil y a la vez, como vimos, ocupa un espacio en su seno. Establece los límites y fronteras de la vida asociativa, incluso de la actividad política. «Obliga a los miembros de las asociaciones a pensar en un bien común, más allá de sus concepciones particulares acerca de la vida digna» (Walzer, 1992: 37) ${ }^{19}$. De hecho, la sociedad civil, por sí sola, puede llegar a generar determinadas relaciones de poder radicalmente desiguales y que solamente podrán ser combatidas por el poder del estado. A su vez, la sociedad civil necesita del estado en el sentido de que éste provee los medios para que las mismas puedan desarrollarse, como por ejemplo a través de las exenciones fiscales a asociaciones, iglesias, partidos; los programas educativos para minorías; las guarderías para los padres y madres trabajadores; las regulaciones para estamentos profesionales, etc. Además, en todo el amplio espectro de las asociaciones, sus miembros individuales pueden necesitar de la protección frente al poder de funcionarios, jefes de estado, de partido, patrones, curas, padres, empleadores, directores, capataces $y$, en general, frente a cualquiera que pueda ejercer poder arbitrario sobre otros, de forma que pueda ser convertido en dominación. En este sentido, dirá Walzer (1992: 37), es necesario «reconocer la importancia real aunque relativa del estado», de forma que éste se convierte en indispensable.

La relación es recíproca, pues sólo un estado de tipo democrático puede crear una sociedad civil democrática y sólo una sociedad civil democrática puede mantener un estado democrático.

Como subraya Cortina, la fuerza de la sociedad civil no solo es real sino también eficaz para la legitimación democrática. En este sentido destaca que «la sociedad civil es también un lugar de justificación y decisión en niveles decisivos» (Cortina, 2011: 32), y subraya su distinción con la política de manera tajante pues «la sociedad civil tiene su espacio propio, que no es el de la política institucional, aunque debe influir en él»

\footnotetext{
19 Cortina reclama que esta exigencia del bien común también debiera hacerse a la inversa, es decir proveniente de la sociedad civil y sus asociaciones hacia los estados que persiguen intereses particularistas, exigencia que considero pertinente y que creo Walzer podría admitir más allá de su omisión. Además, decir que Cortina lo exige también en el sentido de poder buscar un potencial ético universalizador en clave cosmopolita, si bien esto último será rechazado por Walzer, por más que afirme, en consonancia con Cortina, la necesaria búsqueda del bien común por parte de la sociedad civil (este queda limitado a su ámbito de actuación particular). Además, mientras Cortina afirma el valor en sí mismo de la ciudadanía civil, entiende que Walzer lo que busca de la sociedad civil es la utilidad para la política democrática como un simple medio para la ciudadanía política, dejando de lado su valor intrínseco (Cortina, 1997b: 138-139).
} 
(Cortina, 2010: 89; García Marzá, 2013). De este modo, entiende que «existe una esfera institucionalizada de la sociedad civil en la que también se toman decisiones racionalmente justificadas, aunque esa institucionalización no se realice por la vía jurídica» (Cortina, 2011: 32).

Es por esta razón por la que, en el marco de sociedades pluralistas como las descritas por Walzer, Cortina realza el papel que las éticas aplicadas han tenido en relación con la sociedad civil y como se han ido generando instituciones no jurídicas y no parlamentarias en las que también se toman decisiones. En este sentido, al igual que Walzer, defiende la creación de un denso mundo moral, expresión de una ética pública y configurador de un ethos moral, pero que «no se identifica ni con el derecho, ni con redes informales de crítica y protesta», constituyendo así una fenomenización de la ética cívica (Cortina, 2010: 89-90).

En este sentido, dirá Walzer, es necesario fomentar el espíritu cívi$\mathrm{co}^{20}$ a través de las diferentes tramas asociativas, pues solo así podrá extenderse y desarrollarse una política democrática.

A su vez, estas tramas han de ser fomentadas y salvaguardadas por el estado. Frente al estado despótico, la sociedad civil tratará de abrirse paso a través de asociaciones autónomas. Sin embargo, un estado democrático no es sólo el marco para la sociedad civil, pues su relación va más allá y es más estrecha, como hemos tratado de mostrar en líneas precedentes, convirtiéndose también en un instrumento de lucha para dar forma a la vida común que queremos, estableciendo y posibilitando que los ciudadanos puedan ser partícipes junto al mismo estado y no contra él. Es por eso por lo que el concepto de ciudadanía tendrá un papel central en el pensamiento walzeriano a la hora de defender la democracia, el pluralismo y la justicia social. La ciudadanía tendrá cierta preeminencia sobre el resto de afiliaciones que los miembros de la sociedad puedan tener o aspirar a tener, pues es el eje fundamental sobre el que la vida democrática pivotará, por más que ya no se defienda la esfera política como la única y más felicitante para los ciudadanos ${ }^{21}$. Sin embargo, concluye Walzer su reflexión sobre el concepto de sociedad civil diciendo que, el estado debe estar abierto a nuestra implicación y participación, poniendo y facilitando los medios para ello.

20 En este mismo sentido la ética cívica propuesta por Cortina $(1997 ; 1998)$ se define como la ética propia de la sociedad civil.

21 Así pensaban Rousseau y los defensores a ultranza de la democracia participativa. Frente a ellos, y dando también importancia a la participación se erigen otros modelos como la democracia deliberativa y comunicativa, como expone Cortina (2011). 


\section{Conclusiones}

De esta manera, podemos concluir, a modo sumario de lo visto anteriormente, que la política sigue siendo necesaria, que es imprescindible cultivar y fomentar las relaciones y mecanismos oportunos para que los ciudadanos puedan expresarse y participar. En este sentido, hemos visto cómo la sociedad civil y el Estado se necesitan mutuamente, sobre todo en el caso de sociedades democráticas como las descritas.

Hemos visto que la necesidad de gobernanza política sigue siendo hoy una necesidad real, ya que esta esfera juega un papel dual como articuladora y garante del resto de esferas. Para ello, muchas veces tendremos que atender de nuevo a los significados compartidos, repensando las fronteras y redistribuyendo bienes, así como aumentando los mismos y vigilando que los significados y criterios se respeten.

En este sentido, hemos analizado como la corrupción representaba una quiebra de los mismos y una colonización de esferas heterogéneas por parte sobre todo de la esfera económica y política, en las que la intervención irregular de la lógica del dinero y el anhelo de poder e influencia en transacciones y actividades humanas pone en juego otra clase de bienes sociales y recursos. De esta forma, la corrupción constituye siempre un traspaso ilegítimo de fronteras, en el que la quiebra de los significados sociales oportunos es la base para conseguir bienes que no debieran estar al alcance por medios y prácticas no inherentes a los propios significados sociales dados. Además, concluimos que los efectos de la corrupción pueden resultar devastadores, más allá del valor material de los bienes en juego, minando así la confianza en instituciones y erosionando gravemente los fundamentos de la democracia y su funcionamiento.

Frente a ello, podemos afirmar que la esfera política y el papel de la ciudadanía son claves a la hora de poner límites y crear las condiciones para sociedades más justas en las que los propios agentes puedan tener los recursos necesarios para ejercer el control democrático. Asimismo, podemos sostener que la construcción y el uso de canales y espacios de acción común resultan esenciales para que la lucha ciudadana pueda ser real y cristalizar en prácticas reales de movilización, crítica y construcción. En este sentido, tanto el estado como la sociedad civil deben ofrecer tales espacios de deliberación y compromiso cívico, jugando de este modo un papel determinante la esfera política (como articuladora y garante) y el ámbito de la sociedad civil, pues ambas se necesitan de forma imperiosa en la tarea de construir sociedades democráticas fuertes, en las que la ciudadanía se sienta representada y respetada. En cualquier caso, hemos de recordar con Walzer que la esfera política, en la figura del es- 
tado, debe defender los valores de justicia, complejidad e igualdad en representación de los intereses de todos los ciudadanos, pues la inserción de los excluidos comienza con la ciudadanía, como «valor reproducido por la actividad política democrática en todas las esferas de justicia» (Walzer, 1993: 152) y esto, hoy más que nunca, solo puede hacerse desde el reconocimiento de la necesidad de política.

\section{REFERENCIAS}

-Andrés, J. F. (2013). Cicerón y la teoría de la constitución mixta: un enfoque crítico. Cuadernos Electrónicos de Filosofía del Derecho (27), 1-29.

-Barber, B. (2000). Un lugar para todos. Barcelona: Paidós.

-Barber, B. (1984). Strong Democracy: Participatory Politics for a New Age. Berkeley: University of California Press (hay trad. cast. (2004), Democracia fuerte. Politica participativa para una nueva época. Córdoba (España): Almuzara.)

-Chapa, A. (2011). Deliberación pública y forja de la ciudadanía: El despliegue del sujeto en la teoría de la democracia de Benjamin Barber (Tesis de doctorado) Valencia: Universtät de València.

-Cicerón (2001). Los oficios. Madrid: Espasa Calpe.

-Cortina, A. (1994). Del Estado de bienestar al Estado de Justicia. Claves de razón práctica (41), 12-20.

-Cortina, A. (1996). El estatuto de la ética aplicada. Hermenéutica crítica de las actividades Humanas. Isegoría (13), 118-134.

-Cortina, A. (1997). Ética de la sociedad civil, ¿Un antídoto contra la corrupción? En F. J. Laporta y S. Álvarez (Eds.), La corrupción política (págs. 253270). Madrid: Alianza.

-Cortina, A. (1997b). Ciudadanos del mundo. Madrid: Alianza.

-Cortina, A. (1998). Sociedad civil. En A. Cortina (Ed.), Diez.palabras clave en filosofía politica. (págs. 353-387). Pamplona. Verbo Divino.

-Cortina, A. et al. (2003). Construir confianza. Madrid: Trotta.

-Cortina, A. (2010). Justicia cordial. Madrid: Trotta.

-Cortina, A. (2011). Ciudadanía democrática: Ética, política y religión. Isegoría (44), 13-55.

-Conill, J. (2013). Caminos para una justicia global. En E. González (Ed.), Ética y gobernanza: un cosmopolitismo para el siglo XXI (págs. 59-80). Granada: Comares.

-Dekker, P. (2008). La disolución de la sociedad civil: sobre los ideales y las vaguedades en la esfera de las asociaciones de voluntariado. Recerca, revista de pensament $i$ anàlisi (8), 113-133.

-Gamio, G. (2008). Tomar la corrupción en serio. Centro de estudios y publicaciones, 33 (212), 40-45.

-García Marzá, D. (2004). Ética empresarial. Del diálogo a la confianza. Madrid: Trotta. 
-García Marzá, D. (2013). La dimensión ética del diseño institucional. En E. González (Ed.), Ética y gobernanza: un cosmopolitismo para el siglo XXI (págs. 31-58). Granada: Comares.

-García Marzá, D. \& Feenstra, R. A. (2008). Recerca. Revista de Pensament i analisi. Dedicado a "Sociedad civil: una perspectiva crítica" (8). Castellón: Universitat Jaume I.

-Garzón Valdés, E. (1997). Acerca del concepto de corrupción. En F. J. Laporta y S. Álvarez (Eds.), La corrupción política (págs. 39-70). Madrid: Alianza.

-Gil Soldevilla, J. (2004). Una reflexión en torno al concepto de libertad como no-dominación en Walzer y Pettit. Enfoques, XVI (2), 141-150.

-González, E. (Ed.) (2013). Ética y gobernanza: un cosmopolitismo para el siglo XXI. Granada: Comares.

-Lamo, E. (1997). Corrupción política y ética económica. En F. J. Laporta y S. Álvarez (Eds.), La corrupción política (págs. 271-292). Madrid: Alianza.

-Laporta, F. J. (1997). La corrupción política: Introducción general. En F. J. Laporta y S. Álvarez (Eds.), La corrupción politica (39-71). Madrid: Alianza.

-Malem, J. F. (1997). El fenómeno de la corrupción. En F. J. Laporta y S. Álvarez (Eds.), La corrupción política (págs. 71-91). Madrid: Alianza.

-Miller, D. (1995). Introducción. En M. Walzer y D. Miller, Pluralism, Justice, and Equality. Oxford University Press (existe trad. cast. en (1995), Pluralismo, Justicia e Igualdad. Buenos Aires: FCE).

-Shaklar, J. N. (1988). The Faces of Injustice. Yale University Press: New Haven and London: Yale University Press.

-Urbinati, N. (2010). Unpolitical Democracy. Political Theory, 38 (1), 65-92.

-Walzer, M. (1984a). Liberalism and the Art of Separation, Political Theory, 12 (3), 315-330 (hay trad. cast. en (2001), Guerra, politica y Moral. Barcelona: Paidós; y en (2010), Pensar políticamente. Barcelona: Paidós.

-Walzer, M. (1984b). The Secret of Citizenship. The New Republic (191), 34-36.

-Walzer, M. (1986). Justice Here and Now. En F. S. Lucash (Ed.), Justice and Equality Here and Now (págs. 135-150). Itahca: Cornell University Press (hay trad. cast. en (2010), Pensar políticamente. Barcelona: Paidós.)

-Walzer, M. (1989). Citizenship. En T. Ball, J. Farr y R. L. Hanson (Eds.), Political Innovation and Conceptual Change (págs. 211-219). Cambridge: Cambridge University Press.

-Walzer, M. (1992). The Civil Society Argument. En C. Mouffe (Ed.), Dimensions of Radical Democracy: Pluralism, Citizenship, Community (págs. 89-107). London: Verso (hay trad. cast. en (1992), Debats (29), 31-37).

-Walzer, M. (1993). Exclusion, Injustice, and the Democratic State. Dissent (40), 55-64 (hay trad. cast. en (2001), Guerra, política y Moral. Barcelona: Paidós, y en (2010) Pensar políticamente. Barcelona: Paidós).

-Walzer, M. (1995). Education, Democratic Citizenship, and Multiculturalism. Journal of Philosophy of Education, 29 (2), 181-189.

-Walzer, M. (1997). Citizenship in a Changing Society. Berlin, Esprit (hay trad. cast. en (2001), Guerra, política y Moral. Barcelona: Paidós. 
-Walzer, M. (2008). Of course it does. En Does the free market corrode moral character? Investing the big questions. John Templeton Foundation, 20-23.

Sumario: Introducción; I. El problema de la corrupción; 1. Corrupción, mercado y regulación; 2. Condiciones y consecuencias de la corrupción; 3. Buscando antídoto; II. Necesidad de gobernanza política. La esfera política como articuladora y garante; 1 . El carácter dual de la esfera política; 2. Frente a la exclusión y hacia la ciudadanía: necesidad de interpretación e interdisciplinariedad; III. Poder político y sociedad civil; Conclusiones; Referencias. 